\title{
Effects of selected bioactive food compounds on human white adipocyte function
}

Christel Björk ${ }^{1,5^{*}}$, Uta Wilhelm¹, Susanne Mandrup ${ }^{2}$, Bjørk Ditlev Larsen², Alessandra Bordoni ${ }^{3}$, Per Hedén ${ }^{4}$, Mikael Rydén ${ }^{1}$, Peter Arner ${ }^{1}$ and Jurga Laurencikiene ${ }^{1}$

\begin{abstract}
Background: Previous studies suggest that intake of specific bioactive compounds may have beneficial clinical effects on adipose tissue partly due to their anti-inflammatory and insulin-sensitizing properties. With the overall aim to contribute to better understanding of the mechanisms of selected bioactive nutrients on fat metabolism, we investigated their role on human white adipocyte function.

Methods: The influence of the omega-3-fatty acid docosahexaenoic acid (DHA), the anthocyanin (AC) cyanidin-3glucoside and its metabolite protocatechuic acid, and the beta-glucan metabolite propionic acid (PI) on adipokine secretion, fatty acid metabolism (lipolysis/lipogenesis) and adipocyte differentiation (lipid accumulation) was studied in human fat cells differentiated in vitro. To investigate possible synergistic, additive or antagonistic effects, DHA was also combined with AC or PI.

Results: Each compound, alone or together with DHA, suppressed basal adipocyte lipolysis compared to control treated cells. DHA alone attenuated the secretion of pro-inflammatory adipokines such as chemerin, interleukin-6 (IL-6) and monocyte chemoattractant protein-1 (MCP-1/CCL2), whereas AC suppressed only the latter two. Treatment with PI decreased IL-6, tumour necrosis factor alpha (TNFa) and adiponectin secretion. A combination of DHA and AC decreased TNFa secretion and increased insulin-stimulated lipogenesis. No effect was found on adipocyte differentiation. At the selected concentrations, none of the compounds was found to be cytotoxic.

Conclusion: The studied bioactive food compounds or their metabolites have beneficial effects in human primary fat cells measured as decreased basal lipolytic activity and secretion of inflammatory markers. A minor effect was also observed on insulin-stimulated glucose uptake albeit only with the combination of DHA and AC. Taken together, our results may link the reported health benefits of the selected bioactives on metabolic disorders such as insulin resistance, hypertension and dyslipidemia to effects on white adipocytes.
\end{abstract}

Keywords: Anthocyanin, Beta-glucan, Cyanidin-3-glucoside, Docosahexaenoic acid, Inflammation, Insulin sensitivity, Lipolysis, Propionic acid, Protocatechuic acid

\footnotetext{
* Correspondence: christel.bjork@ki.se

'Lipid Laboratory, Department of Medicine, Karolinska Institutet, Huddinge,

Stockholm, Sweden

${ }^{5}$ Department of Medicine, Karolinska Institutet, Lipid Laboratory, Novum, NVS

D4, Hälsovägen 7, 14186 Stockholm, Sweden

Full list of author information is available at the end of the article
} 


\section{Background}

It is well established that white adipose tissue (WAT) metabolism and inflammatory status affect whole body homeostasis [1]. The major role of WAT is to store and release energy. Storing energy in the form of triacylglycerol (TAG) in adipocytes through lipogenesis has been shown to regulate systemic insulin sensitivity [2, 3]. Hydrolysis of TAGs into non-esterified fatty acids and glycerol is a tightly controlled enzymatic process denoted lipolysis. Basal (spontaneous) lipolytic activity is increased in obesity and may attenuate insulin sensitivity through increased delivery of FAs to skeletal muscle (reviewed in [4]). Another important aspect of WAT function is the secretion of a class of proteins called adipokines, several with pro- or anti-inflammatory properties (see [1] for review). An elevated release of monocyte chemoattractant protein-1 (MCP-1/ CCL2) produced by adipocytes [5, 6] recruits macrophages, which in turn promote a chronic low grade inflammation in WAT [7]. Release of other pro-inflammatory adipokines, such as interleukin-6 (IL-6), tumour necrosis factor-alpha (TNF $\alpha$ ) and chemerin may also contribute to metabolic disorders such as insulin resistance, dyslipidemia, hypertension and cardiovascular disease [8-10], which are associated with the development of the metabolic syndrome [11]. The anti-inflammatory adipokine adiponectin has on the other hand been shown to correlate negatively with BMI (Body mass index, defined as body weight in kilograms divided by height in meters squared) and positively with insulin sensitivity $[12,13]$ and its high levels are associated with a lower risk for developing type 2 diabetes [14].

Diet composition can affect the metabolic and endocrine function of WAT as well as overall energy balance [15]. Certain diets that provide high amounts of bioactive components may have beneficial clinical effects partly due to their anti-inflammatory effects on adipose tissue (see $[15,16]$ for reviews). A number of natural bioactive compounds that can be added to the food or their metabolic derivatives have been tested for their action on fat cells. The omega-3 long-chain polyunsaturated fatty acid docosahexaenoic acid (DHA) can be synthesized from the essential alpha-linoleic acid. However, minor (clinically insufficient) amounts are synthesized endogenously and significant levels can only be provided exogenously through intake of fish and fish oil. A previous study using human adipocytes and WAT suggested an anti-inflammatory effect of DHA via decreased levels of IL-6 and MCP-1 [17]. In vitro studies regarding the regulation of DHA on adiponectin production have been performed both in mouse and human adipocytes, however the results are conflicting [18-20]. Anthocyanins (AC) are naturally occurring polyphenol compounds present in blue or purple berries, fruit and vegetables [21]. Cyanidin-3-glucoside (C3G) is the most studied anthocyanin that together with its main metabolite protocatechuic acid (PCA) has been shown to be protective against insulin resistance in both human adipocytes in vitro $[22,23]$ and an in vivo diabetic mouse model $[24,25]$ as well as having anti-inflammatory properties [22, 24-26]. Beta-glucan (BG) is a soluble dietary fiber present in oats and barley. However, BG is not absorbed in vivo, but its metabolism by the gut microbiota results in increased production an uptake of shortchain fatty acids (SCFA), such as propionic acid (PI), which has been shown to regulate adipokine production and enhance lipogenesis and glucose uptake in isolated human WAT $[27,28]$.

Most studies investigating effects of these compounds have been conducted in murine adipose cell lines or in vivo mouse or rat models [29-32], which display a number of species-specific differences concerning adipose tissue function [33-35]. Furthermore, in previous studies the compounds have been tested individually and the experimental conditions as well as fat cell model systems have varied markedly. In addition, in most cases a single metabolic or inflammatory aspect of adipocyte function has been investigated.

As a part of the pan-European study PATHWAY-27 (http://www.pathway27.eu/) with the overall aim to contribute to better understanding of the mechanisms of bioactive nutrients on metabolism in different foodenvironments and help to develop health-promoting food for the growing demand of the health-conscious consumer, we have investigated the role of selected bioactives or their main metabolites on adipocyte phenotypes linked to obesity and the metabolic syndrome.

\section{Methods}

\section{Cell cultures of primary human adipocytes}

Primary human pre-adipocytes for in vitro differentiation from 22 female subjects and 2 male subjects between 26-65 (mean 42) years of age with a BMI ranging from $21-31 \mathrm{~kg} / \mathrm{m}^{2}$ (mean 25) were isolated from the stromal vascular fraction of subcutaneous WAT, which was obtained as a waste product from cosmetic liposuction. Isolation, culture and differentiation into adipocytes were performed as previously described [36]. The subjects were healthy according to self-report and not selected for age, sex or BMI. Briefly, intact pieces of adipose tissue were cut into $3-4 \mathrm{~mm}$ pieces and digested with collagenase for $90 \mathrm{~min}$ at $37^{\circ} \mathrm{C}$, whereas material obtained from liposuctions was digested with collagenase for $45 \mathrm{~min}$ at $37{ }^{\circ} \mathrm{C}$. Thereafter the cell suspension was filtered, centrifuged at $200 \times \mathrm{g}$ for $10 \mathrm{~min}$. The remaining pre-adipocytes and mesenchymal stem cells in the stromal vascular fraction were then suspended in erythrocyte lysis buffer for $10 \mathrm{~min}$ and centrifuged. The 
supernatant was discarded, the cells suspended in proliferation medium containing Dulbecco's Modified Eagle Medium (DMEM)/F12 (Biochrome AG, Berlin, Germany/ Gibco, Life Technologies) supplemented with $10 \%$ fetal bovine serum (Gibco, Life Technologies) and $2 \%$ Pen-Strep (Gibco, Life Technologies) and subsequently filtered through a $70 \mu \mathrm{m}$ cell strainer (BD BioSciences, Durham, NC) .

To study the effects of bioactives on fat cell metabolism and adipokine secretion, the cells were plated in proliferation medium at a density of 115000 to 120000 cells/well in 24-well plates. After $24 \mathrm{~h}$, the medium was changed to DMEM/F12 supplemented with $15 \mathrm{mM}$ HEPES (Gibco, Life Technologies), $100 \mu \mathrm{g} / \mathrm{ml}$ penicillinstreptomycin (Gibco, Life Technologies), $66 \mathrm{nM}$ human insulin, $1 \mathrm{nM}$ triiodo-L-thyronine, $10 \mu \mathrm{g} / \mathrm{ml}$ human transferrin, $33 \mu \mathrm{M}$ biotin, $17 \mu \mathrm{M}$ panthothenate, $100 \mathrm{nM}$ cortisol (all from Sigma St. Louis, MO), $1.25 \mu \mathrm{g} / \mathrm{ml}$ amphotericin B (Gibco, Life Technologies) and $10 \mu \mathrm{M}$ rosiglitazone (BRL49653) (GlaxoSmithKline, Durham, UK) to induce differentiation. Rosiglitazone was included during the first 3-4 days and then removed from the differentiation medium. Medium was changed every 2-3 days and the cells were kept until full differentiation (1214 days). Forty-eight hours before full differentiation, the compounds were added in adipogenic medium.

To investigate the effects of bioactives on lipid accumulation, 20000 cells/well were seeded in 96-well plates. Medium was supplemented with the compounds after 6 days in differentiation medium and treatment was performed for 6 days until day 12 of differentiation. Adipose tissue stromal vascular fraction, which we use to in vitro differentiate adipocytes, contains various cell types including immune cells. At day 6 of differentiation, immune cells are almost entirely washed away and absent and this is the earliest time point in differentiation, where effects unspecific for adipocytes could be excluded. Each experiment was repeated in cells isolated separately from at least three individuals in duplicates (lipid accumulation and lipogenesis) or quadruplicates (lipolysis and adipokine secretion). Cytotoxicity of compounds was measured for all treatment conditions. The grade of differentiation was determined under the microscope and cells with differentiation grade below $80 \%$ were discarded. The study was approved by the Ethics Committee at Karolinska Institutet (Sweden). All subjects were informed about this study and provided their written informed consent.

\section{Treatment with bioactive compounds}

The cells were treated with DHA (D8768, sodium salt, Sigma, St. Louis, MO), C3G (1201-1, chloride salt, Polyphenols Laboratories AS, Sandes, Norway) together with its metabolite PCA (03930590, Sigma) or the BG metabolite PI (P1880, sodium salt, Sigma). To study possible synergistic, additive or antagonistic effects with DHA, the bioactive compound was also studied in combination with AC or PI. Compound concentrations were based on relevant literature [27, 37] and unpublished treatment optimizations in the human Simpson-GolabiBehmel syndrome (SGBS) pre-adipocyte cell line or in a hepatocyte cell line by collaborators in the PATHWAY27 consortium. DHA was coupled to bovine serum albumin (BSA; A6003, Fraction V, Sigma) in a 4:1 ratio. Firstly, BSA was dissolved in $150 \mathrm{mM} \mathrm{NaCl}$ in a $37{ }^{\circ} \mathrm{C}$ water bath and filtered via a sterile $0.2 \mu \mathrm{m}$ polypropylene membrane (VWR International, USA). Shortly after, DHA was dissolved in water and heated to $70{ }^{\circ} \mathrm{C}$ in a water bath. The coupling was performed through mixing both heated solutions and stirring for $1 \mathrm{~h}$ at $37{ }^{\circ} \mathrm{C}$ (pH 7.4). The final DHA concentration in the cell culture medium was 0.5-60 $\mu \mathrm{M}$. C3G was dissolved in phosphatebuffered saline (PBS, Gibco, Life Technologies) whereas its main metabolite PCA was diluted in $50 \% \mathrm{v} / \mathrm{v}$ solution of ethanol in water. According to agreements within the PATHWAY-27 consortium, C3G and PCA were added together to represent $\mathrm{AC}$ in a final concentration of $130 \mathrm{nM}$ and $13 \mu \mathrm{M}$, respectively. PI (P1880, sodium salt, Sigma) was dissolved in $50 \% \mathrm{v} / \mathrm{v}$ solution of ethanol in water and added to the cells at a final concentration of $100 \mu \mathrm{M}$. Corresponding concentrations of BSA and EtOH were added the control samples. As higher concentrations of BSA has been reported to have stimulatory effect on inflammatory cytokine secretion [38], we have performed control experiments comparing BSA and EtOH (at concentrations used in all our treatments) to untreated cells. Such treatment did not affect release of IL-6 and glycerol (Additional file 1: Figure S1).

\section{Cytotoxicity measured as lactate dehydrogenase (LDH) activity in conditioned medium}

Medium from bioactive treated cells was collected when full differentiation was reached. LDH activity, as a measure of damaged cells, was quantified according to the manufacturer's instructions (Cat. No. 11644793 001, Roche Diagnostics GmbH, Mannheim, Germany).

\section{Lipolysis assay}

Conditioned medium was collected after $48 \mathrm{~h}$ of treatment with the bioactive compounds. Basal lipolytic activity was measured as glycerol release with a bioluminescence method using Free Glycerol determination kit from Sigma (FG100) in combination with the fluorescence probe Amplex ultra red reagent (Cat. No. A36006, Molecular Probes, Life Technologies) [39, 40]. Glycerol release was normalized to protein concentration in each cell culture well. 


\section{Lipogenesis}

Determination of basal and insulin-stimulated glucose incorporation into lipids was made when cells reached full differentiation that is after $48 \mathrm{~h}$ of bioactive treatment. Cells were initially washed twice with insulin- and glucose free DMEM (BioChromeAG) and incubated in DMEM containing $1 \mu \mathrm{M}$ glucose. After $3 \mathrm{~h}, 3-{ }^{3} \mathrm{H}$ glucose $(37 \mathrm{MBq} / \mathrm{ml}$; Perkin Elmer-Cetus, Norwalk, CT) diluted 1:1000 in DMEM containing $1 \mu \mathrm{M}$ glucose with was added. For stimulated lipogenesis, insulin was added to a final concentration of $100 \mathrm{nM}$. After $2 \mathrm{~h}$ of incubation, the cells were washed three times with $4{ }^{\circ} \mathrm{C}$ PBS and thereafter lysed in aqueous $0.1 \%$ SDS (sodium dodecyl sulfate, Sigma) solution. An aliquot was saved for protein determination and the rest of the lysate was transferred to scintillation tubes. Toluene scintillation liquid (toluene with $5 \mathrm{~g} / \mathrm{l}$ 2,5-diphenyloxazol and $0.3 \mathrm{~g} / \mathrm{l}$ 1,4-bis (4-methyl-5-phemyl-2-oxazolyl)-benzene; SigmaAldrich) was added and the samples were incubated overnight to extract the lipids. Glucose incorporation into lipids as a proxy of lipogenesis was quantified as $3-{ }^{3} \mathrm{H}$ counts per minute (CPM) using a LS 6500 Multi-Purpose scintillation counter (Beckman, USA).

\section{Adipokine quantification by enzyme-linked immunosorbent assay (ELISA)}

To quantify the secretion of pro- (IL-6, MCP-1, chemerin, and TNF $\alpha$ ) and anti-inflammatory (adiponectin) adipokines, cells were treated with bioactive compounds for $48 \mathrm{~h}$ and conditioned medium was collected for adipokine quantification by ELISA according to the manufacturer's instructions. The samples were diluted 5-60 fold for IL-6 detection (Quantikine ELISA Human IL-6 Immunoassay; R\&D Systems, Minneapolis, MN, Intra-assay precision: $\mathrm{CV}<5 \%$, Inter-assay precision: CV <4 \%), 3-10 fold for MCP-1 (Quantikine ELISA Human CCL3/MCP-1 Immunoassay; R\&D Systems, Intra- and Inter-assay precision: $\mathrm{CV}<6 \%$ ) and 2-10 fold for chemerin (Quantikine ELISA Human Chemerin Immunoassay; R\&D Systems, Intra-assay precision: $\mathrm{CV} \leq 3 \%$, Inter-assay precision: $\mathrm{CV}<6 \%$ to match the standard curve. Adiponectin (Mercodia Adiponectin ELISA; Mercodia AB, Uppsala, Sweden, Intra-assay precision: $\mathrm{CV}<5 \%$, Inter-assay precision: $\mathrm{CV}<8 \%$ ) and TNF $\alpha$ (Quantiglo ELISA Human TNF $\alpha$ Immunoassay; R\&D Systems, Intra-assay precision: $\mathrm{CV}<6 \%$, Inter-assay precision: $\mathrm{CV}<9 \%)$ secretion were measured in undiluted samples. Levels of TNF $\alpha$ were detectable in adipocyte cultures treated with $\mathrm{AC}$ from only two subjects.

\section{Protein quantification}

Protein amount was quantified in SDS lysates from the lipogenesis experiments using Pierce ${ }^{\mathrm{m}}$ BCA Protein Assay Kit (Cat. No. 23225 Pierce, Rockford, IL) according to the manufacturer's instructions. The protein concentration for each well was used to normalize glucose incorporation into lipids as well as glycerol release, LDH activity and adipokine secretion for cell amount.

\section{Neutral lipid and DNA staining}

The cells were differentiated in 96-well plates and treated with the bioactive compounds for 6 days before full differentiation. Medium supplemented with the compounds was added to the cell cultures every second day. Before staining, the cells were washed with PBS and fixed with $4 \%$ paraformaldehyde solution (PFA) containing $0.123 \mathrm{M} \mathrm{NaH}_{2} \mathrm{PO}_{4} \mathrm{xH}_{2} \mathrm{O}, 0.1 \mathrm{M} \mathrm{NaOH}$ and $0.03 \mathrm{M}$ glucose for $10 \mathrm{~min}$ at room temperature. Fixed cells were washed with PBS and stained with Hoechst 33342 $(2 \mu \mathrm{g} / \mathrm{ml}$; staining cell nuclei, Cat. No. H3570, Molecular probes) and Bodipy 493/503 (0.2 $\mu \mathrm{g} / \mathrm{ml}$; staining neutral lipids, Cat. No. D-3922, Molecular probes) diluted in PBS for $20 \mathrm{~min}$ at room temperature. After washing with PBS, accumulation of intracellular lipid droplets and cell number (stained nuclei) were quantified with Acumen eX3 imager (TTP Labtech, Hertfordshire, UK). Bodipy lipid droplet fluorescence was normalized to the amount of nuclei in each well (Hoechst).

\section{Statistical analysis}

The impact of DHA, AC and PI on cytotoxicity, lipid accumulation, adipokine secretion and metabolic outcomes (lipolysis/lipogenesis) was compared to control cells without bioactives. If statistical significance was reached, the effect was also compared with the other bioactives having significant outcomes. Additionally, to investigate possible combinatorial (synergistic, additive or antagonistic) effects of DHA exposure, the impact of DHA alone was compared to that obtained in combination with AC or PI. If a difference was found, AC and PI exposure alone was compared to the effect of the respective bioactive in combination with DHA. The data was tested for normal distribution with the ShapiroWilk test. If the criteria for normal distribution were fulfilled, one-way analysis of variance (ANOVA) with subsequent Tukey's HSD post-hoc test was utilized. When the criteria for normal distribution were not achieved, the non-parametric Kruskal-Wallis and MannWhitney pair-wise comparison tests were used. The level of statistical significance was set as 0.05 with $" p<0.05, " p<0.01$ and ${ }^{* * * *} p<0.001$. Bars are shown as mean \pm standard deviation.

\section{Results}

Titration of the in vitro conditions for DHA treatment of primary human adipocytes

DHA concentrations that have been used in other fat cell systems $(10-60 \mu \mathrm{M})[18-20,41]$ as well as in 
optimizations by PATHWAY-27 collaborators in SGBS cells, induced LDH activity in conditioned media (after 6 days of stimulation) and increased IL- 6 secretion (after $48 \mathrm{~h}$ of stimulation), indicating both cytotoxic and pro-inflammatory effects (Additional file 2: Figure S2). These findings are difficult to reconcile with the reported physiological effects of omega-3fatty acids in vivo [42]. Consequently, the DHA concentration was titrated down and $0.5 \mu \mathrm{M}$ was selected as the highest non-toxic DHA concentration in our primary culture system.

\section{Decreased basal adipocyte lipolysis after treatment with bioactive compounds}

Glycerol release was significantly decreased after all treatments when compared to control, with the exception of $\mathrm{AC}(\mathrm{p}=0.056)$ (Fig. 1). Treatment with PI had the strongest attenuating effect on glycerol release compared to control-treated cells which was stronger than that of DHA $(p=0.009)$. None of the compounds induced cytotoxicity at the selected concentrations, but rather reduced LDH activity in cell cultures after $48 \mathrm{~h}$ of treatment (Additional file 3: Figure S3), except for AC in combination with DHA ( $\mathrm{p}=0.321$, due to a large interindividual variation of the response). LDH activity remained unaltered up after 6 days of treatment with the bioactive compounds.

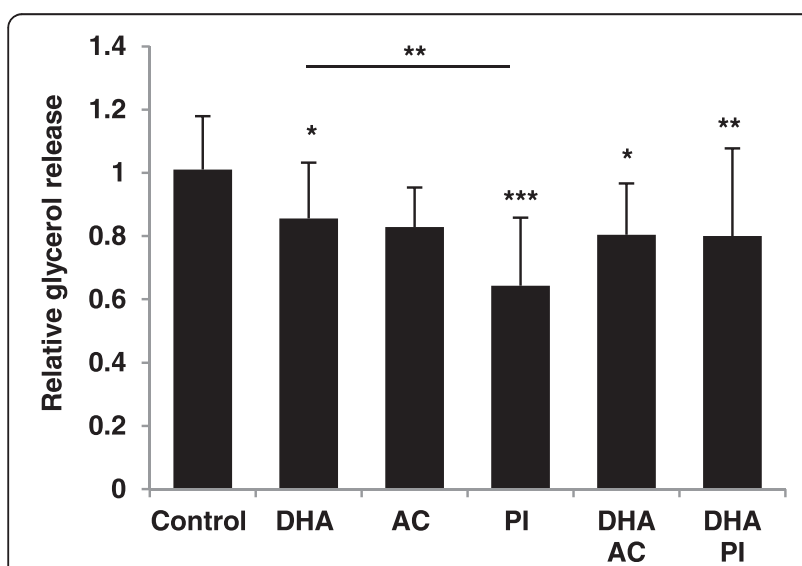

Fig. 1 Decreased basal adipocyte lipolysis after treatment with bioactive compounds or metabolites. Glycerol release after $48 \mathrm{~h}$ of treatment with $0.5 \mu \mathrm{M}$ docosahexaenoic acid (DHA), anthocyanin (AC), that is $130 \mathrm{nM}$ cyanidin-3-glucoside (C3G) and $13 \mu \mathrm{M}$ protocatechuic acid (PCA), and $100 \mu \mathrm{M}$ propionate (PI), relative to control, measured in conditioned medium from human in vitro differentiated adipocytes. Control, $n=9 ; 0.5 \mu M$ DHA, $n=6 ; A C$ alone and with $\mathrm{DHA}, \mathrm{n}=3$; $100 \mu \mathrm{M} \mathrm{PI}$ alone and with DHA, $\mathrm{n}=4$ biological/independent experiments in quadruplicates. Normalized data is adjusted for protein amount and presented as means $+/$ - standard deviation. ${ }^{*} p<0.05,{ }^{* *} p<0.01$ and ${ }^{* *} p<0.001$ versus control. Statistical significance was determined by one-way ANOVA with Tukey's multiple comparisons post hoc test
Combined treatment with DHA and AC increased insulinstimulated adipocyte lipogenesis

To determine the effects of the bioactive compounds or their metabolites on insulin-stimulated lipogenesis, relative glucose incorporation into lipids was measured in the in vitro differentiated primary adipocytes. Insulin induced lipogenesis in the control and all treatment conditions (Fig. 2). No effect on insulin-stimulated response was found after treatment with any of the compounds alone.

However, combined treatment with DHA and AC increased insulin-stimulated glucose uptake compared to the control.

\section{Bioactives alter secretion of pro-inflammatory adipokines and adiponectin}

To investigate the effect of the bioactive compounds or their metabolites on a panel of the most important pro(IL-6, MCP-1, TNF $\alpha$, chemerin) and anti-inflammatory (adiponectin) adipokines, conditioned media from the adipose cells were collected after $48 \mathrm{~h}$ of treatment and secretion was measured by ELISA. IL-6, MCP1 and chemerin secretion were suppressed by DHA (Fig. 3a, b and e). The effect of DHA on MCP-1 and chemerin secretion was also statistically significant in combination with PI (Fig. 3b and e). Additionally, DHA combined with PI impeded TNF $\alpha$ secretion, a

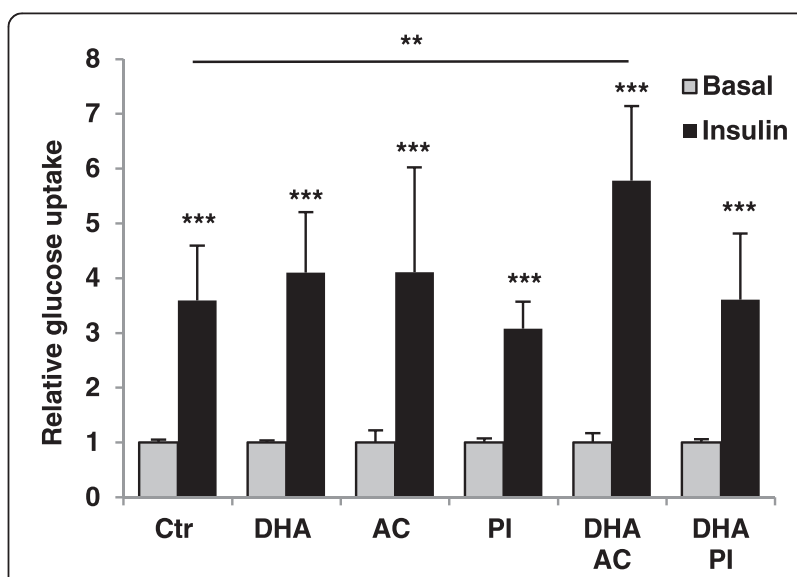

Fig. 2 Combined treatment with DHA and AC increased insulinstimulated adipocyte lipogenesis. Basal and insulin-stimulated lipogenesis measured in cell lysates after $48 \mathrm{~h}$ of treatment with bioactive compounds. Control, $\mathrm{n}=8 ; 0.5 \mu \mathrm{M}$ DHA, $\mathrm{n}=6 ; \mathrm{AC}$ alone and with $\mathrm{DHA}, \mathrm{n}=3 ; 100 \mu \mathrm{MPI}$ alone, $\mathrm{n}=3$ and with $\mathrm{DHA}, \mathrm{n}=4$ biological/independent experiments in duplicates. Glucose incorporation into lipids ( $3-{ }^{3} \mathrm{H}$ counts per minute) is normalized for protein concentration in the cell lysates for each well. Normalized data is presented as means $+/$ - standard deviation. ${ }^{*} p<0.05,{ }^{* *} p<0.01$ and ${ }^{* * *} p<0.001$ counted against basal control with the same bioactive treatment or insulin-stimulated control compared with insulin-stimulated bioactive treated cells. Statistical significance was determined by the non-parametric Kruskal-Wallis test with subsequent Mann-Whitney multiple comparisons post hoc test 

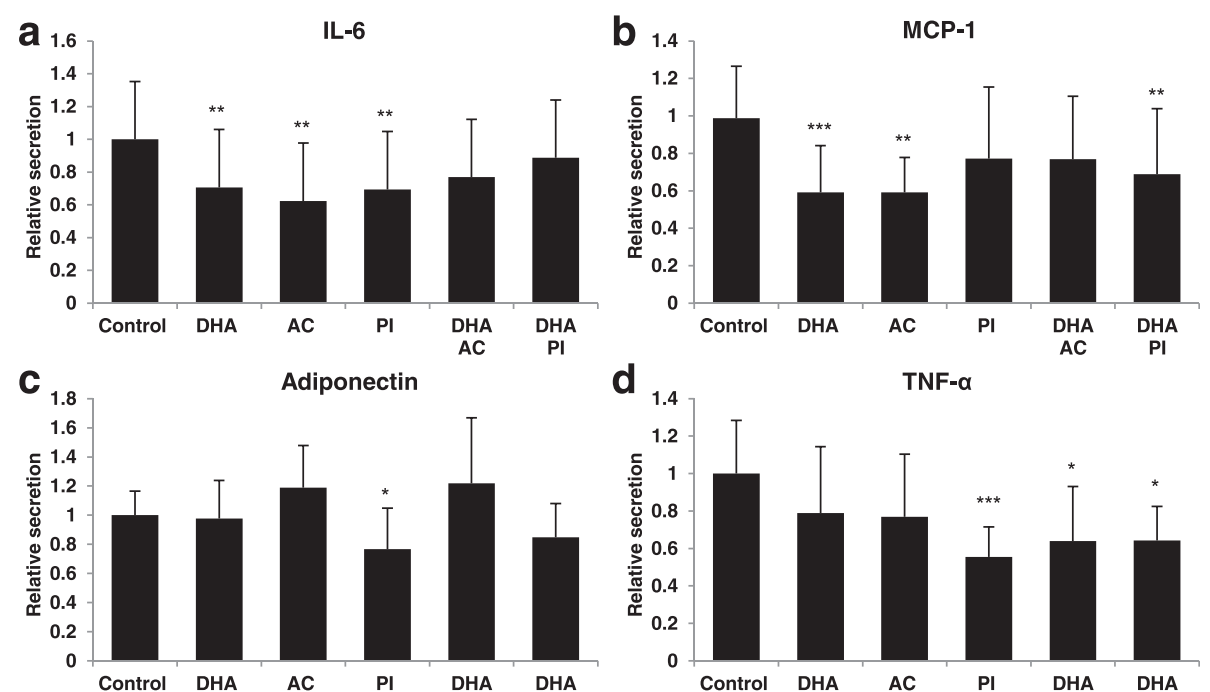

Adiponectin

d
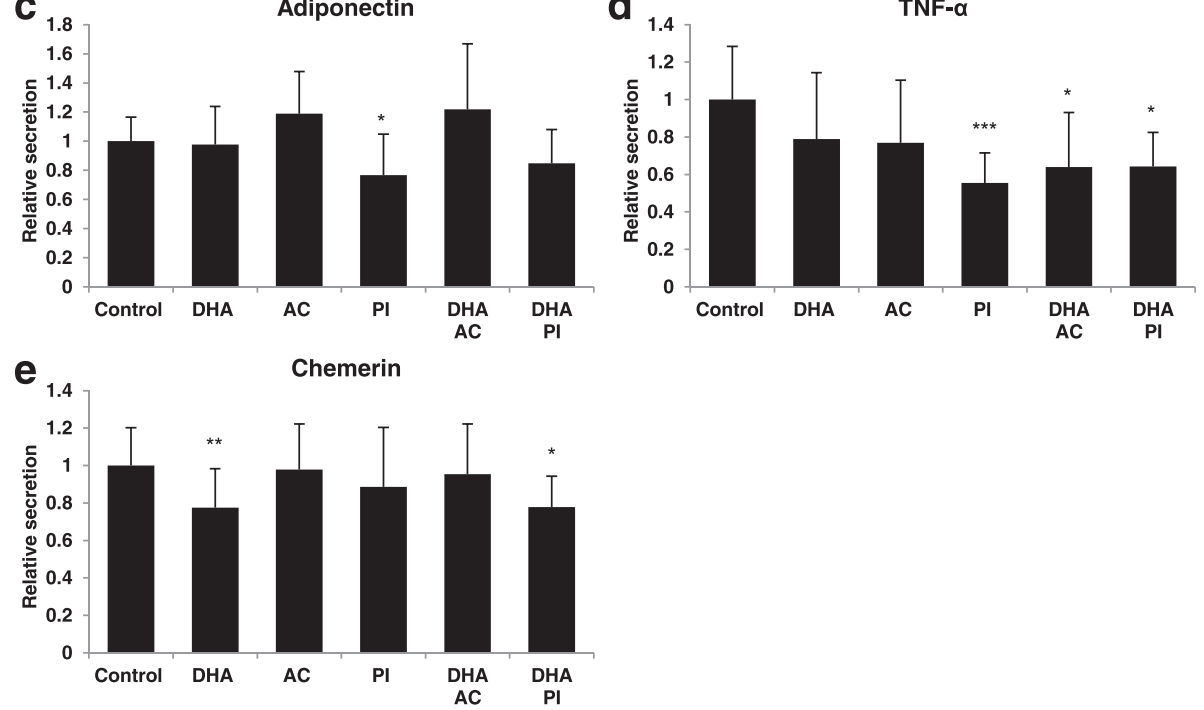

Fig. 3 Bioactives or metabolites alter secretion of pro-inflammatory adipokines and adiponectin. Secretion of adipokines; interleukin-6 (IL-6) (a), monocyte chemoattractant protein-1 (MCP-1) (b), adiponectin (c), tumour necrosis factor a (TNFa) (d) and chemerin (e); after $48 \mathrm{~h}$ of treatment with bioactive compounds relative to control in conditioned media. Control, $n=6-9 ; 0.5 \mu \mathrm{M} \mathrm{DHA}, \mathrm{n}=3-6 ; \mathrm{AC}$ alone and with $\mathrm{DHA}, \mathrm{n}=3 ; 100 \mu \mathrm{M}$ $\mathrm{PI}$ alone and with DHA, $n=3-4$ in biological/independent experiments in quadruplicates, with the exception of TNFa where $n=2-6$ due to levels below minimum detectable dose in four subjects. Normalized data is adjusted for protein amount and presented as means $+/-$ standard deviation. ${ }^{*} p<0.05,{ }^{*} p<0.01$ and ${ }^{* * *} p<0.001$ versus control. Statistical significance was obtained by one-way ANOVA with Tukey's multiple comparisons post hoc test

result that was also obtained with PI alone (Fig. 3d). PI was the only compound that had an effect on adiponectin, contributing to a slightly decreased secretion (Fig. 3c). As the other two compounds, PI suppressed IL- 6 secretion (Fig. 3a). AC alone attenuated IL-6 and MCP-1 secretion and in combination with DHA, demonstrated a suppressed secretion of TNF $\alpha$ (Fig. 3a, b and d).

\section{No effects of bioactives on adipocyte differentiation}

To measure possible effect of bioactives on adipocyte differentiation and lipid accumulation, cells were treated for 6 days and lipid content was measured by Bodipy staining and normalized per cell based on DNA staining by Hoechst (Fig. 4a). No effects were found of the selected compounds on lipid accumulation after 6 days of treatment (Fig. 4b).

\section{Discussion}

Using a systematic assessment of the effects of specific bioactive food compounds and their metabolites in human white fat cells, we found beneficial effects of DHA, AC and PI, either alone or in combination with DHA, on fat cell metabolism and inflammatory phenotype in vitro. The in vitro differentiated non-expanded human primary adipocytes used herein, is the closest model to human fat cells in vivo and enables longer treatments with the compounds. Treatments in in vitro systems always raise a question on the physiological concentrations of the stimuli applied and relevance of the resulting effects for the in vivo situation. We utilized lower concentrations of DHA than that measured in blood [43, 44]. However, higher concentrations of DHA induced cytotoxicity and pro-inflammatory response as in previous studies $[20,45]$. Since the formation of reactive oxygen species (ROS) correlates with the number of double bonds in a polyunsaturated fatty acid, DHA is highly susceptible to spontaneous oxidation. ROS activate surface receptors such as Toll-like receptors which can trigger a downstream signalling cascade, leading to activation of the NF-kappaB pathway, which then turn 


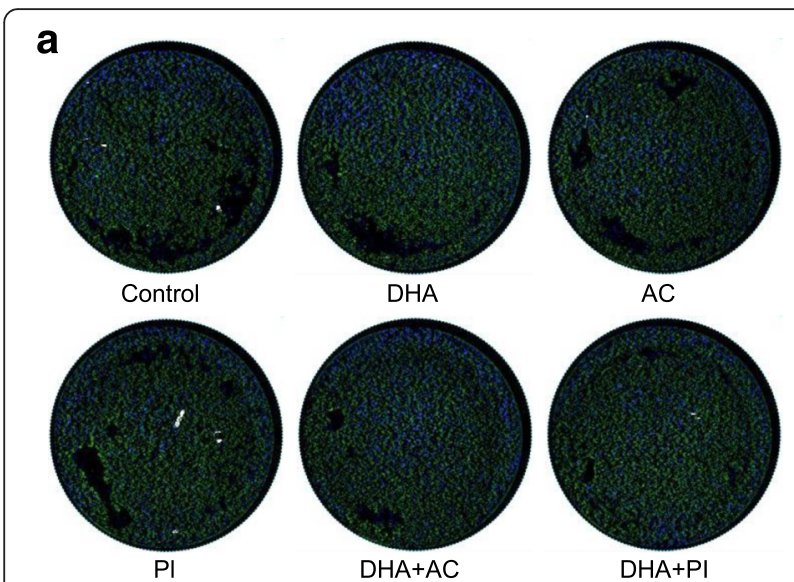

b

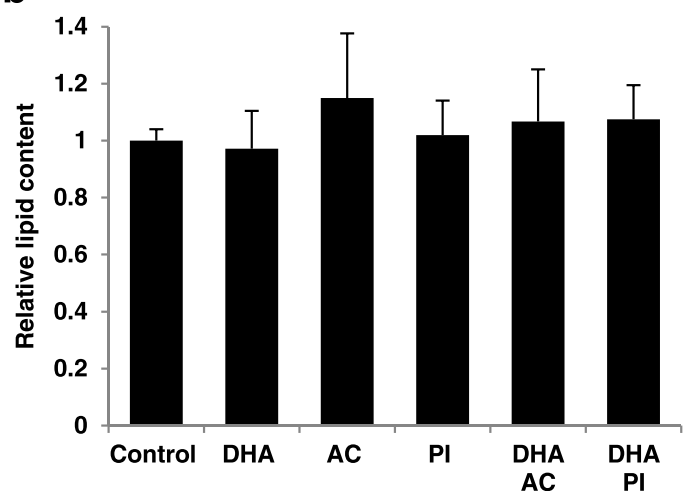

Fig. 4 No effects of bioactives or metabolites on lipid accumulation. Representative pictures of neutral lipid accumulation (green) and cell nuclei (blue) staining after 6 days of treatment with bioactive components (a). Quantified lipid accumulation adjusted for cell amount (control, $\mathrm{n}=8 ; 0.5 \mu \mathrm{M} \mathrm{DHA}, \mathrm{n}=8$; $\mathrm{AC}$ alone and with $\mathrm{DHA}$, $\mathrm{n}=4 ; 100 \mu \mathrm{M} \mathrm{PI}$ alone and with DHA, $\mathrm{n}=6$ biological/independent experiment in duplicates (b). Normalized data is presented as means +/- standard deviation versus control. The absence of statistical significance was determined by the non-parametric Kruskal-Wallis test

on the transcription of many pro-inflammatory genes $[46,47]$. In the support of this hypothesis, ascorbic acid suppressed the pro-inflammatory effect in our primary human adipocyte culture (data not shown). Furthermore, total plasma levels of DHA should not be interpreted as equivalent to local extracellular or intracellular concentrations. To the best of our knowledge, there are no studies that have measured the actual concentration of DHA in adipose tissue. However, we cannot exclude that in the in vivo environment higher concentrations of DHA would be needed for optimal effects. Additionally, none of the other compounds displayed cytotoxicity in our cell cultures and the concentrations used for PI and AC were close to those reported in human blood $[48,49]$.

All three compounds suppressed basal adipocyte lipolysis, where the effect of PI was slightly more pronounced compared with DHA and AC. This could at least in part be due to a fact that PI also significantly attenuated the secretion of TNF $\alpha$, a potent inducer of adipocyte lipolysis [33]. Our finding corroborate results from a study where healthy subjects were supplemented for 4 weeks with non-digestible starch and demonstrated decreased adipose tissue glycerol release as well as reduction in the activity of hormone-sensitive lipase, the rate-limiting enzyme responsible for mobilization of stored TAGs [49]. We therefore suggest that PI might exert its effects at least in part by altering adipocyte lipid metabolism via indirect (through TNF $\alpha$ ) or direct mechanisms. In fact, although the latter mechanism has not been not studied in humans, in mice PI has been suggested to interact with the G-protein coupled receptor 43 [29], a receptor that is suggested to be involved in regulating inflammatory responses, and is also expressed in human WAT [28]. Regarding ACs, an anti-lipolytic effect has been observed in 3T3-L1 adipocytes during hyperglycemia, where $\mathrm{C} 3 \mathrm{G}$ regulated FoxO1-mediated transcription of adipose triglyceride lipase resulting in decreased expression of this lipolytic enzyme [50]. Whether or not this also implies for human adipocytes remains to be investigated. The mechanism of lipolysis reduction by DHA is not known. However, no additive effects between compounds were observed, suggesting that they might act via similar mechanisms.

The synergistic effect between DHA and AC on insulin-induced lipogenesis might partly be explained by the activation of PPARy by $\mathrm{AC}$, which results in increased expression and translocation of GLUT4 [22]. In addition, the effect on lipogenesis could result from decreased TNF $\alpha$ secretion caused by combined DHA and $\mathrm{AC}$ treatment. We and others have shown that TNFa addition in cultures of primary human adipocytes causes insulin resistance [51, 52]. However, a combination of PI and DHA also lowered TNFa secretion but did not affect lipogenesis, which may suggest different mechanisms of action.

Earlier studies both in mice WAT and human adipocytes have shown suppression of pro-inflammatory cytokines by AC [24-26], DHA [17] and PI [27], effects that are generally corroborated in the current study. DHA appears to be the strongest anti-inflammatory compound among the tested ones as this fatty acid decreased expression of three out of four investigated proinflammatory cytokines. We also for the first time report effects of bioactive compounds on chemerin - an insulin resistance inducing cytokine [8], which is largely secreted by adipocytes. DHA was the only compound suppressing chemerin secretion, which was antagonized by AC. Admittedly, at present we do not know how the selected bioactives regulate adipokine secretion, a question which needs further investigations. The outcome of 
compound interaction could also depend on their concentrations, the effects might not be linear and additional experiments using a concentration-dependent response for each bioactive alone and in combination are warranted to better establish any possible additive/ synergistic effects on human adipocytes. However, our data suggest interactions between bioactives on fat cell function, which is relevant for in vivo physiology and nutrition.

Publications from murine 3T3-F442A and -L1 fat cells as well as isolated primary human adipocytes have demonstrated increased adiponectin secretion after DHA treatment $[18,19,53]$. However, it should be noted that fetal bovine serum, an additive which may protect the cells from ROS exposure, was included in the cell culture medium in all these previous studies. This may explain why higher concentrations of DHA could be used in those experiments. Other possible reasons for the discrepancies may be treatment duration or delivery as in vitro cell systems seem to be sensitive to this compound. The effect of PI on adiponectin secretion was unexpected, but could be due to its effect on PPARY reported previously [54]. On the other hand we did not observe any effects of the compounds on fat cell differentiation/ lipid accumulation, which speaks against their possible role regulating important adipogenic factors at least in in vitro cell system.

\section{Conclusions}

Our systematic assessment of DHA, AC and PI, either alone or in combination with DHA, indicate a beneficial role on human fat cell function. The selected compounds decreased basal lipolytic activity and secretion of inflammatory markers in human fat cells which might explain some of the reported health benefits induced by bioactive compound-containing diets in humans, including reduced insulin resistance, hypertension and dyslipidemia $[21,42,55]$. To further elucidate this question, our in vitro results will be used to identify specific biomarkers to be measured in volunteers recruited in a clinical intervention study within the PATHWAY-27 project.

\section{Additional files}

Additional file 1: Figure S1. No effect of $B S A$ and $\mathrm{EtOH}$ on glycerol release or IL-6 secretion. Glycerol release (a) and IL-6 secretion (b) after $48 \mathrm{~h}$ of treatment with $0.05 \%$ Ethanol (EtOH) and $0.125 \mu \mathrm{M}$ bovine serum albumin (BSA) relative to untreated cells in conditioned media ( $n=2$ biological/independent experiments in quintuplicates). Normalized data is adjusted for protein amount and presented as means +/- standard deviation. The absence of statistical significance was determined by Tukey's test. (PPTX $46 \mathrm{~kb}$ )

Additional file 2: Figure S2. Adverse effects of DHA on adipocyte cytotoxicity and IL-6 secretion. Cytotoxicity detection measured as lactate dehydrogenase (LDH) activity in conditioned media after 6 days of treatment with $0.5 \mu \mathrm{M}, 10 \mu \mathrm{M}$ or $60 \mu \mathrm{M} \mathrm{DHA}$, relative to control (a). Control, $n=7 ; 0.5 \mu \mathrm{M}$ DHA, $n=3 ; 10 \mu \mathrm{M}$ and $60 \mu \mathrm{M}$ DHA $n=2$ biological/independent experiments in at least duplicates. Secretion of IL-6 from human in vitro differentiated adipocytes after $48 \mathrm{~h}$ of treatment with $0.5 \mu \mathrm{M}, 5 \mu \mathrm{M}, 10 \mu \mathrm{M}, 20 \mu \mathrm{M}, 30 \mu \mathrm{M}$ or $60 \mu \mathrm{M}$ DHA compared to control (b). Control, $\mathrm{n}=2$ and $\mathrm{DHA} \mathrm{n}=1$ biological/independent experiments in triplicates. Normalized data is adjusted for protein amount and presented as means $+/$ - standard deviation. ${ }^{*} p<0.05$, ${ }^{* *} p<0.01$ and ${ }^{* * *} p<0.001$ versus control. Statistical significance was obtained by one-way ANOVA with Tukey's multiple comparisons post hoc test. (PPTX $47 \mathrm{~kb}$ )

Additional file 3: Figure S3. Decreased cytotoxicity after treatment with bioactive compounds or metabolites. Lactate dehydrogenase (LDH) activity after 48 h or 6 days treatment with bioactive compounds relative to control in conditioned media. Forty-eight hours; control, $n=9 ; 0.5 \mu \mathrm{M}$ $\mathrm{DHA}, \mathrm{n}=6 ; \mathrm{AC}$ alone and with $\mathrm{DHA}, \mathrm{n}=3 ; 100 \mu \mathrm{M} \mathrm{PI}$ alone and with DHA, $n=4$ biological/independent experiments in quadruplicates; 6 days; control, $n=7 ; 0.5 \mu \mathrm{M} \mathrm{DHA}, \mathrm{n}=7$; AC alone and with $\mathrm{DHA}, \mathrm{n}=4 ; 100 \mu \mathrm{M}$ $\mathrm{PI}$ alone and with $\mathrm{DHA}, \mathrm{n}=5$ biological/independent experiments in duplicates. Normalized data is adjusted for protein amount in each well as a measure of cell amount and presented as means +/- standard deviation. ${ }^{*} p<0.05,{ }^{* *} p<0.01$ and ${ }^{* * *} p<0.001$ versus control. Statistical significance was determined by one-way ANOVA with Tukey's multiple comparisons post hoc test. (PPTX $44 \mathrm{~kb}$ )

\section{Abbreviations}

AC: anthocyanin; BG: beta-glucan; BMI: body mass index; BSA: bovine serum albumin; C3G: cyanidin-3-glucoside; CPM: counts per minute;

DHA: docosahexaenoic acid; ELISA: enzyme-linked immunosorbent assay; LDH: lactate dehydrogenase; IL-6: interleukin-6; MCP-1/ CCL2: monocyte chemoattractant protein-1; PCA: protocatechuic acid; PI: propionic acid; PFA: paraformaldehyde solution; PBS: phosphate-buffered saline: PPARY: Peroxisome Proliferator-Activated Receptor Gamma; SCFA: shortchain fatty acid; SDS: sodium dodecyl sulfate; SGBS: Simpson-GolabiBehmel syndrome; TAG: triacylglycerol; TNFa: tumour necrosis factoralpha; WAT: white adipose tissue.

\section{Competing interests}

The authors declare that they have no conflict of interests.

\section{Authors' contributions}

Conception and design (CB, SM, AB, MR, PA, JL); acquisition, analysis and interpretation of data (all co-authors), drafting the article (CB, UW, MR, PA, $\mathrm{JL})$; critical revising of the manuscript and final approval of the version to be published (all co-authors).

\section{Acknowledgements}

The research leading to these results has received funding from the European Union Seventh Framework Programme (FP7/2007-2013) under grant agreement $n^{\circ} 311876$ : Pathway-27, the Swedish Research Council and Karolinska Institutet. We thank Stefan Storcksdieck, Caroline Orfila and Samantha Sutulic from the PATHWAY-27 consortium (www.pathway27.eu) for assisting with preparation of the manuscript. The excellent technical assistance of Gaby Åström, Elisabeth Dungner and Kerstin Wåhlen is greatly appreciated.

\section{Author details}

'Lipid Laboratory, Department of Medicine, Karolinska Institutet, Huddinge, Stockholm, Sweden. ${ }^{2}$ Department of Biochemistry and Molecular Biology, University of Southern Denmark, 5230 Odense M, Denmark. ${ }^{3}$ Department of Agro-Food Sciences and Technologies, University of Bologna, Bologna, Italy. ${ }^{4}$ Department of Plastic Surgery, Akademikliniken, Stockholm, Sweden.

${ }^{5}$ Department of Medicine, Karolinska Institutet, Lipid Laboratory, Novum, NVS D4, Hälsovägen 7, 14186 Stockholm, Sweden.

Received: 13 August 2015 Accepted: 14 January 2016 Published online: 19 January 2016 


\section{References}

1. Maury E, Brichard SM. Adipokine dysregulation, adipose tissue inflammation and metabolic syndrome. Mol Cell Endocrinol. 2010;314:1-16.

2. Bays $H$, Mandarino $L$, DeFronzo RA. Role of the adipocyte, free fatty acids, and ectopic fat in pathogenesis of type 2 diabetes mellitus: peroxisomal proliferator-activated receptor agonists provide a rational therapeutic approach. J Clin Endocrinol Metab. 2004;89:463-78.

3. Hoffstedt J, Forster D, Lofgren P. Impaired subcutaneous adipocyte lipogenesis is associated with systemic insulin resistance and increased apolipoprotein B/Al ratio in men and women. J Intern Med. 2007;262:131-9.

4. Arner P, Langin D. Lipolysis in lipid turnover, cancer cachexia, and obesityinduced insulin resistance. Trends Endocrinol Metab. 2014;25:255-62.

5. Christiansen T, Richelsen B, Bruun JM. Monocyte chemoattractant protein-1 is produced in isolated adipocytes, associated with adiposity and reduced after weight loss in morbid obese subjects. Int J Obes (Lond) 2005;29:146-50

6. Dahlman I, Kaaman M, Olsson T, Tan GD, Bickerton AS, Wahlen K, et al. A unique role of monocyte chemoattractant protein 1 among chemokines in adipose tissue of obese subjects. J Clin Endocrinol Metab. 2005;90:5834-40

7. Weisberg SP, McCann D, Desai M, Rosenbaum M, Leibel RL, Ferrante Jr AW. Obesity is associated with macrophage accumulation in adipose tissue. J Clin Invest. 2003;112:1796-808.

8. Bozaoglu K, Bolton K, McMillan J, Zimmet P, Jowett J, Collier G, et al. Chemerin is a novel adipokine associated with obesity and metabolic syndrome. Endocrinology. 2007;148:4687-94.

9. Fried SK, Bunkin DA, Greenberg AS. Omental and subcutaneous adipose tissues of obese subjects release interleukin-6: depot difference and regulation by glucocorticoid. J Clin Endocrinol Metab. 1998;83:847-50.

10. Sewter CP, Digby JE, Blows F, Prins J, O'Rahilly S. Regulation of tumour necrosis factor-alpha release from human adipose tissue in vitro. J Endocrinol. 1999:163:33-8.

11. Grundy SM, Brewer Jr HB, Cleeman JI, Smith Jr SC, Lenfant C. Definition of metabolic syndrome: Report of the National Heart, Lung, and Blood Institute/American Heart Association conference on scientific issues related to definition. Circulation. 2004;109:433-8.

12. Arita Y, Kihara S, Ouchi N, Takahashi M, Maeda K, Miyagawa J, et al. Paradoxical decrease of an adipose-specific protein, adiponectin, in obesity. Biochem Biophys Res Commun. 1999;257:79-83.

13. Hoffstedt J, Arvidsson E, Sjolin E, Wahlen K, Arner P. Adipose tissue adiponectin production and adiponectin serum concentration in human obesity and insulin resistance. J Clin Endocrinol Metab. 2004;89:1391-6.

14. Li S, Shin HJ, Ding EL, van Dam RM. Adiponectin levels and risk of type 2 diabetes: a systematic review and meta-analysis. JAMA. 2009;302:179-88.

15. Siriwardhana N, Kalupahana NS, Cekanova M, LeMieux M, Greer B, Moustaid-Moussa N. Modulation of adipose tissue inflammation by bioactive food compounds. J Nutr Biochem. 2013;24:613-23.

16. Rosa FT, Zulet MA, Marchini JS, Martinez JA. Bioactive compounds with effects on inflammation markers in humans. Int J Food Sci Nutr. 2012;63:749-65.

17. Murumalla RK, Gunasekaran MK, Padhan JK, Bencharif K, Gence L, Festy F, et al. Fatty acids do not pay the toll: effect of SFA and PUFA on human adipose tissue and mature adipocytes inflammation. Lipids Health Dis. 2012;11:175.

18. Banga A, Unal R, Tripathi P, Pokrovskaya I, Owens RJ, Kern PA, et al. Adiponectin translation is increased by the PPARgamma agonists pioglitazone and omega-3 fatty acids. Am J Physiol Endocrinol Metab. 2009;296:E480-489.

19. Tishinsky JM, Ma DW, Robinson LE. Eicosapentaenoic acid and rosiglitazone increase adiponectin in an additive and PPARgamma-dependent manner in human adipocytes. Obesity (Silver Spring). 2011;19:262-8.

20. Warnke I, Goralczyk R, Fuhrer E, Schwager J. Dietary constituents reduce lipid accumulation in murine $\mathrm{C} 3 \mathrm{H} 10 \mathrm{~T} 1 / 2$ adipocytes: A novel fluorescent method to quantify fat droplets. Nutr Metab (Lond). 2011;8:30.

21. He J, Giusti MM. Anthocyanins: natural colorants with health-promoting properties. Annu Rev Food Sci Technol. 2010;1:163-87.

22. Scazzocchio B, Vari R, Filesi C, D'Archivio M, Santangelo C, Giovannini C, et al. Cyanidin-3-O-beta-glucoside and protocatechuic acid exert insulin-like effects by upregulating PPARgamma activity in human omental adipocytes. Diabetes. 2011;60:2234-44
23. Scazzocchio B, Vari R, Filesi C, Del Gaudio I, D'Archivio M, Santangelo C, et al. Protocatechuic acid activates key components of insulin signaling pathway mimicking insulin activity. Mol Nutr Food Res. 2015;59:1472-81.

24. Guo H, Xia M, Zou T, Ling W, Zhong R, Zhang W. Cyanidin 3-glucoside attenuates obesity-associated insulin resistance and hepatic steatosis in high-fat diet-fed and $\mathrm{db} / \mathrm{db}$ mice via the transcription factor FoxO1. J Nutr Biochem. 2012;23:349-60.

25. Sasaki R, Nishimura N, Hoshino H, Isa Y, Kadowaki M, Ichi T, et al. Cyanidin 3-glucoside ameliorates hyperglycemia and insulin sensitivity due to downregulation of retinol binding protein 4 expression in diabetic mice. Biochem Pharmacol. 2007;74:1619-27.

26. Tsuda T, Ueno Y, Yoshikawa T, Kojo H, Osawa T. Microarray profiling of gene expression in human adipocytes in response to anthocyanins. Biochem Pharmacol. 2006;71:1184-97.

27. Al-Lahham S, Roelofsen H, Rezaee F, Weening D, Hoek A, Vonk R, et al. Propionic acid affects immune status and metabolism in adipose tissue from overweight subjects. Eur J Clin Invest. 2012;42:357-64.

28. Al-Lahham SH, Roelofsen H, Priebe M, Weening D, Dijkstra M, Hoek A, et al. Regulation of adipokine production in human adipose tissue by propionic acid. Eur J Clin Invest. 2010;40:401-7.

29. Ge H, Li X, Weiszmann J, Wang P, Baribault H, Chen JL, et al. Activation of G protein-coupled receptor 43 in adipocytes leads to inhibition of lipolysis and suppression of plasma free fatty acids. Endocrinology. 2008;149:4519-26.

30. Han JH, Kim IS, Jung SH, Lee SG, Son HY, Myung CS. The effects of propionate and valerate on insulin responsiveness for glucose uptake in 3 T3-L1 adipocytes and C2C12 myotubes via G protein-coupled receptor 41. PLoS One. 2014;9:e95268.

31. Heimann E, Nymann M, Degerman E. Propionic acid and butyric acid inhibit lipolysis and de novo lipogenesis and increase insulin-stimulated glucose uptake in primary rat adipocytes. Adipocyte. 2014;4:1-8.

32. Hong YH, Nishimura Y, Hishikawa D, Tsuzuki H, Miyahara H, Gotoh C, et al. Acetate and propionate short chain fatty acids stimulate adipogenesis via GPCR43. Endocrinology. 2005;146:5092-9.

33. Arner P. Human fat cell lipolysis: biochemistry, regulation and clinical role. Best Pract Res Clin Endocrinol Metab. 2005;19:471-82.

34. Mikkelsen TS, Xu Z, Zhang X, Wang L, Gimble JM, Lander ES, et al. Comparative epigenomic analysis of murine and human adipogenesis. Cell. 2010;143:156-69.

35. Rosen ED, Spiegelman BM. What we talk about when we talk about fat. Cell. 2014;156:20-44.

36. van Harmelen V, Skurk T, Hauner H. Primary culture and differentiation of human adipocyte precursor cells. Methods Mol Med. 2005;107:125-35.

37. Wang YC, Kuo WH, Chen CY, Lin HY, Wu HT, Liu BH, et al. Docosahexaenoic acid regulates serum amyloid A protein to promote lipolysis through down regulation of perilipin. J Nutr Biochem. 2010;21:317-24.

38. Schlesinger JB, van Harmelen V, Alberti-Huber CE, Hauner H. Albumin inhibits adipogenesis and stimulates cytokine release from human adipocytes. Am J Physiol Cell Physiol. 2006;291:C27-33.

39. Hellmer J, Arner P, Lundin A. Automatic luminometric kinetic assay of glycerol for lipolysis studies. Anal Biochem. 1989;177:132-7.

40. Stenson BM, Ryden M, Venteclef N, Dahlman I, Pettersson AM, Mairal A, et al. Liver $X$ receptor (LXR) regulates human adipocyte lipolysis. J Biol Chem. 2011;286:370-9.

41. Murali G, Desouza CV, Clevenger ME, Ramalingam R, Saraswathi V. Differential effects of eicosapentaenoic acid and docosahexaenoic acid in promoting the differentiation of 3 T3-L1 preadipocytes. Prostaglandins Leukot Essent Fatty Acids. 2014:90:13-21.

42. Lorente-Cebrian S, Costa AG, Navas-Carretero S, Zabala M, Martinez JA, Moreno-Aliaga MJ. Role of omega-3 fatty acids in obesity, metabolic syndrome, and cardiovascular diseases: a review of the evidence. J Physiol Biochem. 2013;69:633-51.

43. Attar-Bashi NM, Weisinger RS, Begg DP, Li D, Sinclair AJ. Failure of conjugated linoleic acid supplementation to enhance biosynthesis of docosahexaenoic acid from alpha-linolenic acid in healthy human volunteers. Prostaglandins Leukot Essent Fatty Acids. 2007;76:121-30.

44. Pawlosky RJ, Hibbeln JR, Herion D, Kleiner DE, Salem Jr N. Compartmental analysis of plasma and liver n-3 essential fatty acids in alcohol-dependent men during withdrawal. J Lipid Res. 2009;50:154-61.

45. Kim HK, Della-Fera M, Lin J, Baile CA. Docosahexaenoic acid inhibits adipocyte differentiation and induces apoptosis in 3 T3-L1 preadipocytes. J Nutr. 2006;136:2965-9. 
46. Shi H, Kokoeva MV, Inouye K, Tzameli I, Yin H, Flier JS. TLR4 links innate immunity and fatty acid-induced insulin resistance. J Clin Invest. 2006;116:3015-25

47. Ruan H, Hacohen N, Golub TR, Van Parijs L, Lodish HF. Tumor necrosis factor-alpha suppresses adipocyte-specific genes and activates expression of preadipocyte genes in 3 T3-L1 adipocytes: nuclear factor-kappaB activation by TNF-alpha is obligatory. Diabetes. 2002;51:1319-36.

48. Czank C, Cassidy A, Zhang Q, Morrison DJ, Preston T, Kroon PA, et al. Human metabolism and elimination of the anthocyanin, cyanidin-3glucoside: a (13)C-tracer study. Am J Clin Nutr. 2013;97:995-1003.

49. Robertson MD, Bickerton AS, Dennis AL, Vidal H, Frayn KN. Insulin-sensitizing effects of dietary resistant starch and effects on skeletal muscle and adipose tissue metabolism. Am J Clin Nutr. 2005;82:559-67.

50. Guo H, Guo J, Jiang X, Li Z, Ling W. Cyanidin-3-O-beta-glucoside, a typical anthocyanin, exhibits antilipolytic effects in 3 T3-L1 adipocytes during hyperglycemia: involvement of FoxO1-mediated transcription of adipose triglyceride lipase. Food Chem Toxicol. 2012;50:3040-7.

51. Chuang CC, Bumrungpert A, Kennedy A, Overman A, West T, Dawson B, et al. Grape powder extract attenuates tumor necrosis factor alphamediated inflammation and insulin resistance in primary cultures of human adipocytes. J Nutr Biochem. 2011;22:89-94.

52. Pettersson AM, Acosta JR, Bjork C, Kratzel J, Stenson B, Blomqvist L, et al. MAFB as a novel regulator of human adipose tissue inflammation. Diabetologia. 2015:58:2115-23.

53. Oster RT, Tishinsky JM, Yuan Z, Robinson LE. Docosahexaenoic acid increases cellular adiponectin mRNA and secreted adiponectin protein, as well as PPARgamma mRNA, in 3 T3-L1 adipocytes. Appl Physiol Nutr Metab. 2010;35:783-9.

54. Besten GD, Bleeker A, Gerding A, van Eunen K, Havinga R, van Dijk TH, et al. Short-chain fatty acids protect against high-fat diet-induced obesity via a PPARgamma-dependent switch from lipogenesis to fat oxidation. Diabetes. 2015;64:2398-408.

55. El Khoury D, Cuda C, Luhovyy BL, Anderson GH. Beta glucan: health benefits in obesity and metabolic syndrome. J Nutr Metab. 2012;2012:851362.

\section{Submit your next manuscript to BioMed Central and we will help you at every step:}

- We accept pre-submission inquiries

- Our selector tool helps you to find the most relevant journal

- We provide round the clock customer support

- Convenient online submission

- Thorough peer review

- Inclusion in PubMed and all major indexing services

- Maximum visibility for your research

Submit your manuscript at www.biomedcentral.com/submit 